\title{
Food protein-stabilized nanoemulsions as potential delivery systems for poorly water-soluble drugs: preparation, in vitro characterization, and pharmacokinetics in rats
}

\author{
This article was published in the following Dove Press journal: \\ International Journal of Nanomedicine \\ 10 March 2011 \\ Number of times this article has been viewed
}

Wei He'
Yanan Tan'
Zhiqiang Tian'
Lingyun Chen'
Fuqiang Hu'
Wei Wu'
'Department of Pharmaceutics,
School of Pharmacy, Fudan University,
Shanghai, People's Republic of China;
'Department of Agricultural, Food
and Nutritional Sciences, University
of Alberta, Alberta, Canada; ${ }^{3}$ Department
of Pharmaceutics, School of Pharmacy,
Zhejiang University, Hangzhou,
Zhejiang, People's Republic of China

Zhejiang, People's Republic of China

\begin{abstract}
Nanoemulsions stabilized by traditional emulsifiers raise toxicological concerns for long-term treatment. The present work investigates the potential of food proteins as safer stabilizers for nanoemulsions to deliver hydrophobic drugs. Nanoemulsions stabilized by food proteins (soybean protein isolate, whey protein isolate, $\beta$-lactoglobulin) were prepared by highpressure homogenization. The toxicity of the nanoemulsions was tested in Caco-2 cells using the 3-(4,5-dimethylthiazol-2-yl)-2,5-diphenyltetrazoliumbromide viability assay. In vivo absorption in rats was also evaluated. Food protein-stabilized nanoemulsions, with small particle size and good size distribution, exhibited better stability and biocompatibility compared with nanoemulsions stabilized by traditional emulsifiers. Moreover, $\beta$-lactoglobulin had a better emulsifying capacity and biocompatibility than the other two food proteins. The pancreatic degradation of the proteins accelerated drug release. It is concluded that an oil/water nanoemulsion system with good biocompatibility can be prepared by using food proteins as emulsifiers, allowing better and more rapid absorption of lipophilic drugs.
\end{abstract}

Keywords: oil in water nanoemulsions, food proteins, poorly water-soluble drugs, biocompatibility, in vivo absorption

\section{Introduction}

Nanoemulsions are nonequilibrium, heterogeneous systems consisting of two immiscible liquids in which one liquid is dispersed in another liquid as droplets with diameters of tens to a few hundred nanometers. Oil/water nanoemulsions have great potential for the delivery of poorly water-soluble drugs. ${ }^{1-3}$ The major advantages of nanoemulsions as drug delivery carriers include ease of fabrication, increased drug loading, enhanced drug solubility and bioavailability, reduced patient variability, controlled drug release, and protection from enzymatic degradation. ${ }^{1,4}$ To stabilize nanoemulsions, a large amount of surfactant $(20 \%-30 \%$ based on the oil phase, wt $\%)$ must be used in the formulations, which hinders the therapeutic application of nanoemulsions due to toxicological concerns during long-term treatment. ${ }^{5-8}$ Another main problem with nanoemulsions is their thermodynamic instability, resulting in aggregation and flocculation; furthermore, loading a drug into a nanoemulsion system can cause droplet coalescence and even phase separation. ${ }^{9-11}$ Therefore, it is necessary to develop stable nanoemulsions using alternative safer surfactants.

Food biopolymers, especially food proteins, are widely used in formulated foods because they have high nutritional value and are generally recognized as safe. ${ }^{12,13}$
Correspondence: Wei Wu

Department of Pharmaceutics, School of Pharmacy,

Fudan University, Shanghai 20I203,

People's Republic of China

Tel/Fax +862I 5l980002

Email wuwei@shmu.edu.cn 
These proteins include soybean protein isolate (SPI), whey protein isolate (WPI), and $\beta$-lactoglobulin $(\beta-\lg ) .{ }^{12}$ SPI is a plant protein obtained from an abundant, inexpensive, and renewable resource, the soybean. It is composed almost exclusively of two globular protein fractions called $7 \mathrm{~S}$ ( $\beta$-conglycinin) and 11S (glycinin). ${ }^{14} 11 \mathrm{~S}$ has a hexameric structure with a molecular weight of 300-380 kDa and an isoelectric point of 4.8 , whereas $7 \mathrm{~S}$ has a structure of canavalin and phaseolin with a molecular weight of 18-21 kDa and an isoelectric point of $6.4 .{ }^{15}$ The amount of nonpolar amino acid residues is $62.5 \%(\mathrm{~mol} \%)$ and $34.8 \%$ for $11 \mathrm{~S}$ and $7 \mathrm{~S}$, respectively. ${ }^{16}$ WPI is derived from milk, in which the two most important proteins ( $\beta$-lg and $\alpha$-lactalbumin) account for about $65 \%$ of the total weight of whey protein. ${ }^{17,18}$ $\alpha$-Lactalbumin is a small, acidic, and $\mathrm{Ca}^{2+}$-binding milk protein with a molecular weight of $14.2 \mathrm{kDa}$ and an isoelectric point of 4-5. Native $\alpha$-lactalbumin, consisting of 123 amino acid residues, has two domains, ie, a large $\alpha$-helical domain and a small $\beta$-sheet domain, which are connected by a calcium binding loop. ${ }^{19} \beta$-lg, which is widely used as a food ingredient, is a dominant globular protein in WPI. It has a molecular weight of $18.4 \mathrm{kDa}$ and an isoelectric point of 5.2. ${ }^{20}$ Each monomer comprises 162 amino acids, with one free cysteine and two disulphide bridges. ${ }^{20,21}$ The proteins, like traditional surfactants, are amphiphilic. However, food proteins possess good water solubility and can function as excellent wall materials. ${ }^{22-24}$ Thus, food proteins have better flexibility than surfactants and can adsorb rapidly to the emulsion interface, where they self-aggregate through intermolecular interactions and form continuous membranes around oil droplets. ${ }^{12,18}$ The hydrophobic residues (amino acids and disulfide bonds), to some extent, are buried in the protein interior, which is directly correlated with the surface tension reduction at the oil/water interface. After heat denaturation, nonpolar and disulfide bonds buried inside the protein will become exposed, which can enhance the ability of these proteins to adsorb to the emulsion interface. ${ }^{25}$ Most importantly, these food proteins have excellent biocompatibility and biosafety due to their ready biodegradation by proteases. ${ }^{13,26-30}$ Therefore, we hypothesize that food proteins are safer emulsifiers for nanoemulsions, which has potential for the delivery of poorly water-soluble drugs.

Fenofibrate (FB), a Biopharmaceutics Classification System Class II drug, is a highly lipophilic drug that is clinically used to lower lipid levels. Its therapeutic efficacy has been compromised for years due to virtual water insolubility in water and physiological fluids. It was reported that lipid-based formulations enhanced its oral bioavailability efficiently. ${ }^{31-33}$
The colloidal structures formed during the digestion of lipids provide a series of enduring lipophilic phases within which lipophilic drugs might reside during gastrointestinal transit, preventing precipitation and enhancing absorption of the drugs. ${ }^{34}$

In the present work, our aim was to evaluate the ability of the food proteins to stabilize nanoemulsions. Considering the difference in structure, molecular weight, surface characteristics, and isoelectric points, three representative proteins, SPI, WPI, and $\beta$-lg, were chosen in our study. The nanoemulsions were characterized in terms of particle size and distribution, zeta potential, transmission electron microscopy (TEM) morphology, and resistance to centrifugation. The toxicity of food protein-stabilized nanoemulsions was evaluated in Caco-2 cells using the 3-(4,5-dimethylthiazol-2-yl)-2, 5-diphenyltetrazoliumbromide (MTT) viability assay. Specifically, a representative poorly water-soluble drug, FB, was loaded into oil/water nanoemulsions, and then in vitro release and pharmacokinetics in rats were evaluated.

\section{Materials and methods Materials}

FB was purchased from Enhua Pharma Co., Ltd (Xuzhou, China). WPI was provided by Davisco Foods International Inc. (Le Sueur, MN, USA). SPI was obtained from Hufeng Chemical Industry Co., Ltd (Shanghai, China). $\beta$-lg from bovine milk (No. L3908, >90\% purity grade) was purchased from Sigma Chemical Co. (St Louis, MO, USA). Cremophor EL, Cremophor RH 40, Poloxamar-188, and Solutol HS15 were from BASF (Ludwigshafen, Germany). Polysorbate 80 (Tween-80) was supplied by Shenyu Pharmaceutical and Chemical Co., Ltd (Shanghai). Egg phosphatidylcholine (EPC) was purchased from Toshisun Co., Ltd (Shanghai). Medium-chain triglycerides (Labrafac Lipophile WL 1349), used as the oil phase, were kindly provided by Gattefossé Co. (Saint Priest, Cedex, France). Caco-2 cells were purchased from the American Type Culture Collection (Manassas, VA, USA). Dulbecco's Modified Eagle Medium and Hank's balanced salt solution (HBSS) were purchased from Genom Biotech Co., Ltd (Hangzhou, China). Deionized water was prepared using a Milli-Q purification system (Millipore, Billerica, MA, USA). MTT was from Sigma Chemical Co. (St Louis). All other chemicals were of analytical grade and were used as received.

\section{Preparation of nanoemulsions}

Protein solutions ( $8 \%$ WPI, 8\% SPI, and $1 \% \beta-\lg , \mathrm{w} / \mathrm{v})$ in water were prepared as described previously by Chen and 
Subirade $^{29}$ and Chen et al. ${ }^{35}$ Briefly, WPI, SPI, and $\beta-\lg$ solutions were prepared by dispersing the protein powder into deionized water with stirring for 1 hour at $25^{\circ} \mathrm{C}$. The solution was then adjusted to $\mathrm{pH} 7.0$ using $1 \mathrm{M}$ sodium hydroxide. To denature the nonpolar and disulfide bonds buried in the protein interior and thus increase the emulsifying capacity of the proteins, the SPI, WPI, and $\beta$-lg solutions were heated to $105^{\circ} \mathrm{C}, 85^{\circ} \mathrm{C}$, and $85^{\circ} \mathrm{C}$, respectively, in closed centrifuge tubes $(50 \mathrm{~mL}$, Corning Incorporated, MA, USA) for 30 minutes (Figure 1A). The denatured protein solution was then cooled to $25^{\circ} \mathrm{C}$ for 2 hours.

Blank nanoemulsions were prepared using a two-step procedure. A coarse emulsion was prepared by homogenizing oil phase with aqueous phase using a high-speed Ultra-Turrax blender (QilinBeier, Jiangsu, China) operating at 20,000 rpm for 0.5 minutes. Afterwards, the emulsions were further homogenized using a high-pressure homogenizer (ATS Engineering, Inc., Ontario, Canada) (Figure 1A). To compare the emulsifying capacities of the proteins and other surfactants, nanoemulsions using EPC, Cremophor EL and RH 40,

A

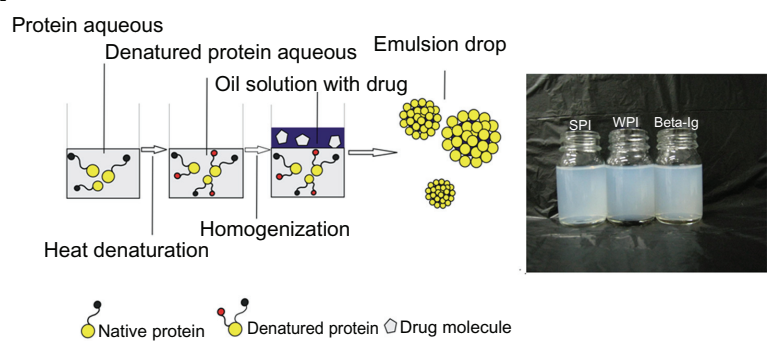

B
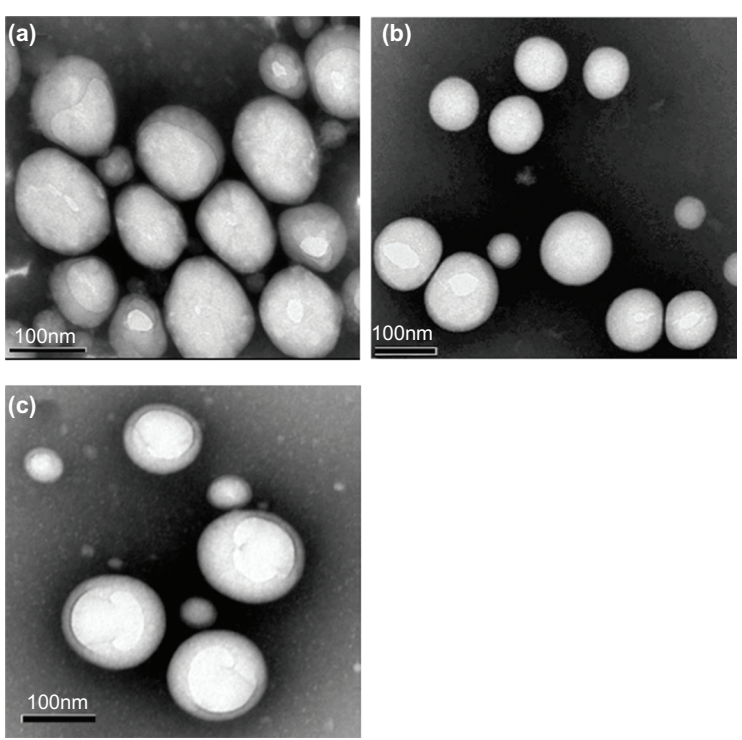

Figure I A) Scheme of the process for preparing protein-stabilized nanoemulsions and photographs of nanoemulsions. B) Transmission electron microphotography of food protein-stabilized nanoemulsions: soy protein isolate (SPI), whey protein isolate (WPI), and $\beta$-lactoglobulin $(\beta-\mathrm{lg})$. The scale bar for all images represents $100 \mathrm{~nm}$.
Poloxamar-188, Solutol HS15, or Tween-80 as emulsifiers were also prepared, in which the concentration of emulsifier was $1.5 \% \mathrm{w} / \mathrm{v}$, following a similar procedure to that described previously. The nanoemulsions containing FB were prepared in the same manner by dissolving FB in the oil phase in advance.

\section{Particle size and zeta potential determination}

The mean particle size and the size distribution of the nanoemulsions were measured by dynamic light scattering (DLS) using a NICOMP 380 DLS instrument (Santa Barbara, CA, USA). The nanoemulsion was diluted 500 -fold in deionized water before measurement.

The surface charge of the nanoemulsions was investigated by measuring the electrophoretic mobility at $25^{\circ} \mathrm{C}$ using a NICOMP 380 ZLS. Nanoemulsions were diluted 50-fold in water before measurement.

\section{Physical stability of nanoemulsions}

The stability of the nanoemulsions was evaluated using the centrifugal acceleration method. ${ }^{36}$ Briefly, $4 \mathrm{~mL}$ of nanoemulsion was placed in a $5 \mathrm{~mL}$ Eppendorf tube and centrifuged at $3000 \mathrm{~g}$ for 10 minutes in a desktop centrifuge (Anke TGL-16G, Shanghai). A $0.8 \mathrm{~mL}$ sample of the subnatant was withdrawn from the bottom of the tube into a pipette with a slow and steady motion. Then, the samples were vortex mixed for 20 seconds, and $0.1 \mathrm{~mL}$ of the samples was transferred to a $50 \mathrm{~mL}$ volumetric flask and diluted with deionized water to the desired final volume. The absorbance of the diluted nanoemulsions was determined spectrophotometrically at a wavelength of $500 \mathrm{~nm}$. The constant of centrifugal stability $(\mathrm{Ke})$ was calculated according to the following formula: ${ }^{37}$

$$
k e=\frac{\left|A_{0}-A\right|}{A_{0}} \times 100 \%
$$

where $\mathrm{A}_{0}$ and $\mathrm{A}$ are the absorbance of the diluted nanoemulsion before and after centrifugation, respectively.

\section{TEM}

TEM was used to characterize the morphology of the nanoemulsions. Nanoemulsions were placed on copper grids and negatively stained with $2 \%(\mathrm{w} / \mathrm{v})$ phosphotungstic acid for 5 minutes at room temperature. Finally, the grids bearing nanoemulsions were observed with a JEM-1230 transmission electron microscope (JEOL, Tokyo, Japan). 


\section{In vitro cytotoxicity of nanoemulsions}

The cytotoxicity of the nanoemulsions was tested by measuring the viability of Caco-2 cells in the presence of varying concentrations of blank nanoemulsions. The viability of the cells was measured using the MTT assay. Caco- 2 cells were seeded on 96-well plates at a density of $1 \times 10^{4}$ cells per well and cultured for 72 hours. Then, the cell culture medium was removed from each well, and the cells were rinsed three times with HBSS. Nanoemulsions diluted in HBSS were added to each well, and the cells were incubated for 4 hours at $37^{\circ} \mathrm{C}$. Five wells were used to test each sample. Next, $20 \mu \mathrm{L}$ of MTT solution $(5 \mathrm{mg} / \mathrm{mL})$ was added to each well and allowed to incubate at $37^{\circ} \mathrm{C}$ for 4 hours. The growth medium and excess MTT in each well were removed. Dimethylsulfoxide $(150 \mu \mathrm{L})$ was added to each well to completely dissolve the internalized purple formazan crystals. The $490 \mathrm{~nm}$ absorbance of each well was measured spectrophotometrically. The cytotoxicity of the nanoemulsions was expressed as the percentage of cell viability, which was calculated from the ratio between the number of cells treated with the nanoemulsions to that of the control cells (blank). Cells treated with sodium dodecyl sulfate solution $(0.5 \mathrm{mg} / \mathrm{mL})$ were used to define $0 \%$ cell viability; cells exposed to HBSS were used to define $100 \%$ cell viability. Cell viability was calculated according to the following equation:

$$
\text { Cell viability }(\%)=\frac{A_{\text {test }}}{A_{\text {control }}} \times 100 \%
$$

where $\mathrm{A}_{\text {test }}$ and $\mathrm{A}_{\text {control }}$ were the absorbance of cells treated with nanoemulsions and of cells treated with HBSS, respectively.

\section{In vitro drug release}

The release profiles of FB from protein-stabilized nanoemulsions were performed using a dialysis method. Aliquots of nanoemulsions $(0.4 \mathrm{~mL})$ were instilled into dialysis tubing (14,000 MW cut-off). Release testing was carried out in a ZRS-8G release tester (Tianjin, China) according to the Chinese Pharmacopoeia Method III (the small beaker method). The dialysis bags were placed in a beaker containing $100 \mathrm{~mL}$ of release medium and maintained at $37^{\circ} \mathrm{C}$ with a paddle revolution speed of $50 \mathrm{rpm}$. The release medium was either simulated gastric fluid (SGF) (0.1 M hydrogen chloride with or without $0.32 \%[\mathrm{w} / \mathrm{v}]$ pepsin) or simulated intestinal fluid (SIF) (pH 6.8 phosphate buffer with or without $1 \%[\mathrm{w} / \mathrm{v}]$ pancreatin), each of which contained $2 \%$ Cremophor EL (w/v) to maintain a sink condition. At various time intervals, $0.5 \mathrm{~mL}$ of the samples was withdrawn, and after centrifugation at 10,600 $\mathrm{g}$ for 5 minutes the FB concentrations in the samples were determined by high-performance liquid chromatography (HPLC). Measurements were conducted in triplicate.

\section{Pharmacokinetic study}

The bioavailability of SPI-, WPI-, and $\beta$-lg-stabilized nanoemulsions containing FB was evaluated in rats and compared with the bioavailability of FB dissolved in oil. Sprague Dawley rats (adult male, 250-270 g) used in the experiments received care in compliance with the Principles of Laboratory Animal Care and the Guide for the Care and Use of Laboratory Animals. Experiments followed protocol approved by the Fudan University Institutional Animal Care and Use Committee.

The rats were fasted but were allowed free access to water for 12 hours before the experiments. The formulations were orally administered by gavage to rats at an FB dosage equivalent to $30 \mathrm{mg} / \mathrm{kg}$. The formulations of protein-stabilized nanoemulsions consisted of $0.5 \% \mathrm{FB}, 1.5 \%$ protein, and $6 \%$ oil solution. FB oil solution (control) was prepared by dissolving $75 \mathrm{mg}$ of FB in $15 \mathrm{~mL}$ of oil. After gavage, blood samples $(0.2 \mathrm{~mL})$ were collected from the tail vein into heparinized tubes at the following time points: $0.25,0.5$, $0.75,1,2,4,6,8,12,24$, and 36 hours. The heparinized blood samples were immediately centrifuged at $3000 \mathrm{~g}$ for 10 minutes in a desktop centrifuge (Anke TGL-16G), and the plasma was separated and transferred to microcentrifuge tubes. The plasma samples were frozen at $-18^{\circ} \mathrm{C}$ until analysis.

Pharmacokinetic parameters were calculated by noncompartmental analysis based on statistical moment theory using Microsoft Excel 2003. The pharmacokinetic parameters, such as maximum plasma concentration $\left(C_{\max }\right)$ and time of maximum concentration $\left(T_{\max }\right)$, were obtained directly from the plasma concentration-time plots. The area under the plasma concentration-time curve up to the last time $(t)\left(A U C_{0-t}\right)$ was calculated using the linear trapezoidal rule.

\section{HPLC assay}

As a prodrug, FB is rapidly metabolized to its major active metabolite, fenofibric acid. After oral administration and absorption, no intact FB can be detected in the plasma. ${ }^{38}$ Therefore, pharmacokinetic evaluation of FB is based on the quantification of fenofibric acid in plasma.

The sample preparation and HPLC procedures were similar to those described in our previous report. ${ }^{32}$ The Agilent 1100 series HPLC system (Agilent, Santa Clara, CA, USA) consisted of a quaternary pump, a degasser, an auto 
sampler, a column heater, and a tunable ultraviolet detector. Fenofibric acid was separated at $30^{\circ} \mathrm{C}$ using a $\mathrm{C} 18$ column (Diamonsil, $5 \mu \mathrm{m}, 4.6 \mathrm{~mm} \times 250 \mathrm{~mm}$, Dikma, China) with a refillable C18 precolumn $(2.0 \mathrm{~mm} \times 20 \mathrm{~mm}$, Alltech, Lexington, KT, USA) and detected by measuring the $287 \mathrm{~nm}$ absorbance of the eluate. Indomethacin $(100 \mu \mathrm{g} / \mathrm{mL})$ was used as an internal standard. The mobile phase was a mixture of methanol/water/phosphoric acid (70:30:0.1, v/v/v) pumped at a flow rate of $1 \mathrm{~mL} / \mathrm{min}$.

\section{Statistical analysis}

The results were expressed as mean \pm standard deviation. One-way analysis of variance was performed to assess the statistical significance of differences among samples. Results with $P<0.05$ were considered statistically significant.

\section{Results and discussion Preparation and characterization of nanoemulsions}

WPI and $\beta$-lg dissolved rapidly in water yielding homogenous and clear solutions, whereas SPI dissolved partially in water yielding a turbid suspension. After heat denaturation, WPI and $\beta-\lg$ solutions remained clear, whereas the viscosity of the SPI dispersion decreased significantly. The heating procedure was intended to improve the emulsifying capacity of the proteins by breaking the disulfide bonds buried inside the protein. ${ }^{25}$ The food protein-stabilized nanoemulsions were prepared using a combination of mechanical mixing and high-pressure homogenization (Figure 1A). The coarse emulsions prior to homogenization were typically a few microns in size, yet they exhibited a wide distribution under photomicroscopy. After homogenization, milky white nanoemulsions were obtained (Figure 1A) and the particle size was reduced dramatically. After homogenization at 800 bars for 10 cycles, the particle size of the nanoemulsions was further reduced to between $200 \mathrm{~nm}$ and $250 \mathrm{~nm}$ with a $\log$ normal distribution. No drug precipitation was observed during the preparation of protein-stabilized nanoemulsions containing FB. Furthermore, an increase of drug in formulations would not result in drug precipitation. TEM photographs of the food protein-stabilized nanoemulsions revealed a spherical morphology with particle diameters ranging from $150 \mathrm{~nm}$ to $250 \mathrm{~nm}$ (Figure 1B), closely corresponding to the results obtained by DLS.

It is well known that particle size and distribution, as well as physical stability, exert significant influence on the bioavailability of nanoemulsions. In this study, we investigated the effects of homogenization pressure and number of homogenization cycles, protein concentration, oil-to-water ratio, and $\mathrm{pH}$ on particle size, polydispersity index (PI), and physical stability of the nanoemulsions. Furthermore, a comparison of the emulsifying capacity of the three food proteins with that of several surfactants was also performed.

\section{Effect of homogenization pressure and number of homogenization cycles}

Nanoemulsions with good dispersion can be obtained using a high-pressure homogenizer. Figure 2(A-1/B-1) shows the effect of homogenization pressure and cycles on $\mathrm{Ke}$, particle size, and polydispersity. A considerable decrease in particle size and PI was achieved with an increase in pressure homogenization and/or the number of cycles. Increasing the pressure from 100 bars to 800 bars and the number of cycles from 1 to 10 led to a significant reduction in particle size and PI, with the $\beta$-lg-stabilized nanoemulsions having the smallest particle size. However, further increasing the homogenization pressure to 1000 bars and the number of cycles to $30 \mathrm{did}$ not result in significant smaller particle sizes due to the increased surface area and interfacial tension caused by the high homogenization energy input. ${ }^{39} \mathrm{PI}$ is a measure of dispersion homogeneity with values ranging from 0 to 1 . PI values lower than 0.3 suggest a homogeneous dispersion. ${ }^{40}$ The nanoemulsions stabilized by food proteins revealed a relatively small particle size ranging from about $200 \mathrm{~nm}$ to $250 \mathrm{~nm}$ and a very narrow size distribution (PI $<0.2$ ) when a homogenization pressure of 800 bars was applied for 10 cycles.

Figure 2(A-2/B-2) depicts the effect of homogenization pressure and number of cycles on the physical stability of nanoemulsions. It was observed that the $K e$ decreased markedly with an increase in pressure and number of cycles (1 to 10), indicating an enhanced stability of the nanoemulsions. The nanoemulsion stabilized by $\beta-\lg$ was the most stable. It has been reported that an increase in homogenization pressure and number of cycles can improve surfactant adsorption to the surface of emulsion drops, which plays an important role in the stabilization of nanoemulsions. ${ }^{41}$ However, increasing the number of homogenization cycles beyond 10 would not further improve the stability of nanoemulsions. When the number of homogenization cycles increased to more than 10 , the stability of nanoemulsion stabilized by WPI and SPI decreased. The log-normal size distribution in particle size became bimodal distribution with an increased fraction of larger particles (data not shown), owing to too much energy input to the nanoemulsions. 


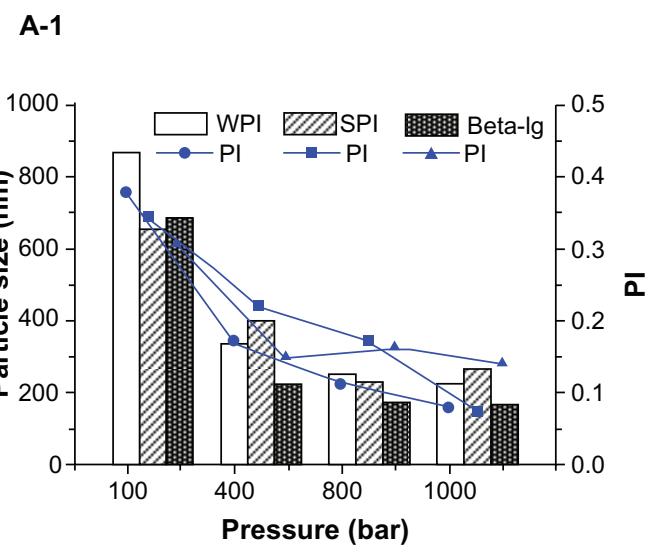

B-1

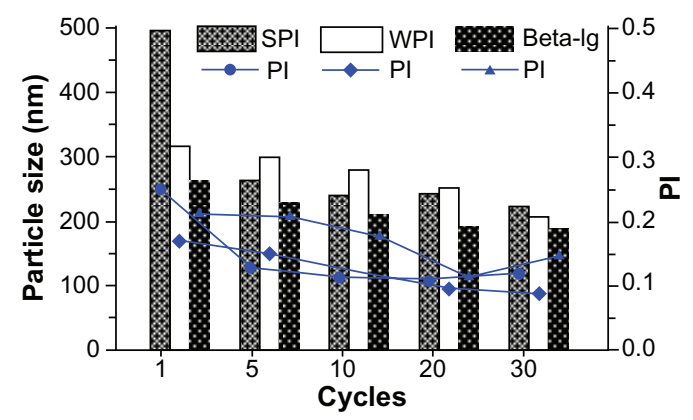

A-2

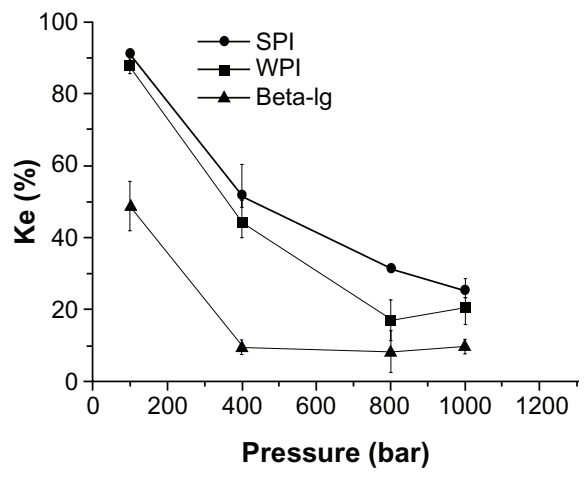

B-2

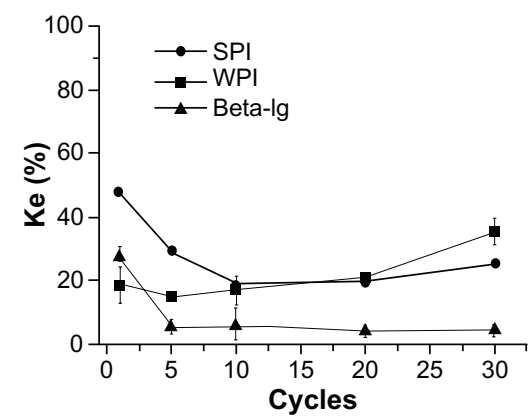

Figure 2 A) Effect of homogenization pressure on centrifugal stability (Ke), mean particle size, and polydispersity index (PI) of food protein-stabilized nanoemulsions. The number of homogenization cycles for the prepared nanoemulsions was I0. A-I) Effect of homogenization pressure on mean particle size (column graph) and PI (line graph). A-2) Effect of homogenization pressure on Ke.B) Effect of cycle number on Ke, mean particle size, and Pl of food protein-stabilized nanoemulsions. The homogenization pressure for the prepared nanoemulsions was 800 bars. B-I) Effect of cycle number on mean particle size (column graph) and PI (line graph). B-2) Effect of cycle number on Ke. Abbreviations: $\beta$-lg, $\beta$-lactoglobulin; SPI, soy protein isolate; WPI, whey protein isolate.

\section{Effect of protein concentration}

It is known that the concentration of stabilizers influences the particle size and polydispersity of an emulsion. Increasing the concentrations of SPI and $\beta-\lg$ led to decreases in particle size (Figure 3A). However, increasing concentrations of WPI led to negligible changes in particle size, probably owing to the fact that the surfaces of the droplets were saturated with WPI at concentrations greater than $1 \% .{ }^{42}$ The particle size of $\beta$-lg-stabilized nanoemulsions was much smaller than that of the nanoemulsions stabilized by WPI or SPI. PI decreased significantly with increasing protein concentrations, indicating an improvement in the particle size distribution of the nanoemulsions.

Figure 3B depicts the influence of stabilizer concentration on nanoemulsion stability. $\mathrm{Ke}$ decreased with increasing concentrations of SPI and WPI, indicating an improved stability of the nanoemulsions. It was explained that the bimodal size distribution in particle size became a narrower and log-normal distribution with an increase in concentrations, along with a decrease in the number of large particles (data not shown). It has also been reported that greater protein concentrations result in larger electrostatic repulsive forces between colliding droplets. ${ }^{43}$ It was observed that the $\mathrm{Ke}$ of $\beta$-lg-stabilized nanoemulsions was not affected markedly by $\beta$-lg concentration, likely due to greater surface charge of $\beta$-lg relative to SPI and WPI. In fact, the $\mathrm{Ke}$ value of nanoemulsions prepared using the lowest concentration of $\beta-\lg (1 \%)$ was not greater than the corresponding values for WPI and SPI at the highest concentration (8\%), highlighting the potent stabilizing effect of $\beta$-lg. Intrinsically, it could be ascribed to the exposure of more hydrophobic domains on the surface of $\beta-\lg$ than that of WPI and SPI, which was directly correlated with the probability of its adsorption and retention at the interface. ${ }^{44}$

\section{Effect of oil-to-water ratio}

The effect of the oil-to-water ratio is shown in Figure 4. For the protein-stabilized nanoemulsions, increasing the oil phase volume fraction from 5\% to 50\% resulted in an increase in particle size from $250 \mathrm{~nm}$ to $300 \mathrm{~nm}$ and from $250 \mathrm{~nm}$ to $400 \mathrm{~nm}$ for WPI- and SPI-stabilized nanoemulsions, respectively; the homogeneous dispersion was also affected 
(A)

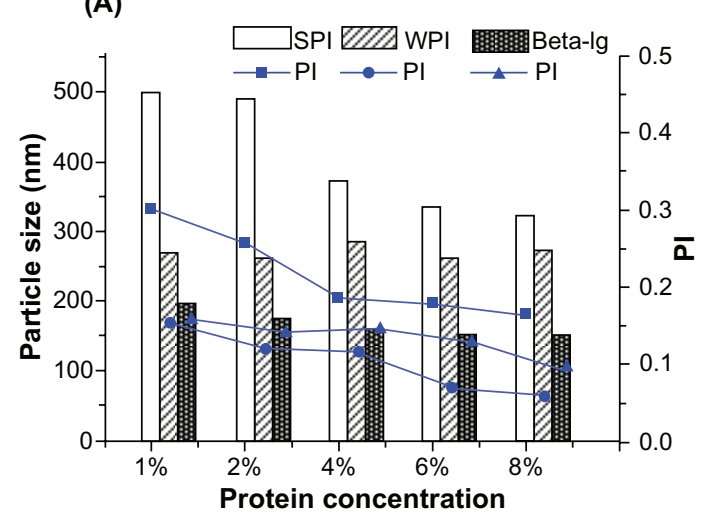

(B)

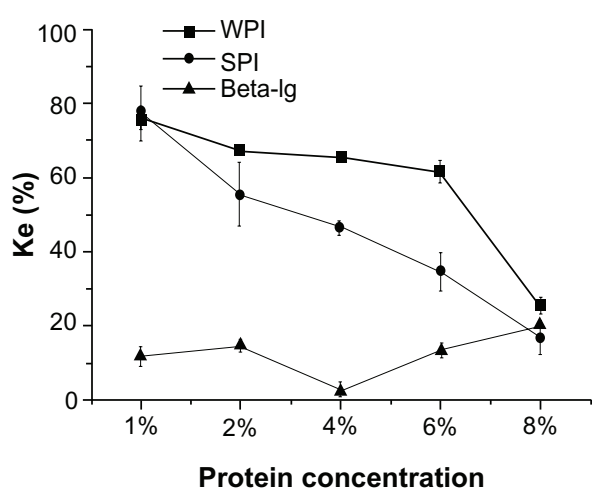

Figure 3 Effect of protein concentration on centrifugal stability $(K e)$, mean particle size, and polydispersity index $(\mathrm{PI})$ of protein-stabilized nanoemulsions. The nanoemulsions were prepared using the optimized processing conditions, ie, 800 bars and 10 cycles. A) Effect of protein concentration on mean particle size (column graph) and PI (line graph). B) Effect of protein concentration on Ke. Abbreviations: $\beta$-lg, $\beta$-lactoglobulin; SPI, soy protein isolate; WPI, whey protein isolate.

by the oil volume because the PI was increased (Figure 4A). The preceding observation can be attributed to the increase in the interfacial surface caused by increasing the oil volume. Interestingly, no influence of the oil phase volume on the particle size and PI of nanoemulsions stabilized by $\beta-\lg$ was observed, underscoring its efficient emulsification and its greater drug-carrying capacity. ${ }^{10}$

The $\mathrm{Ke}$ of $\beta$-lg- and SPI-stabilized nanoemulsions decreased when the oil phase volume fraction was less than $25 \%$, whereas the $K e$ increased when the fraction was greater than $25 \%$. The turning point of $K e$ from WPI-stabilized nanoemulsions was also at the $25 \%$ fraction; however, the changing trend of $\mathrm{Ke}$ was the opposite (Figure 4B); it was ascribed to the change of size distribution in particle size. It seemed that the stability of $\beta$-lg- and SPI-stabilized nanoemulsions was more sensitive to variation of the oil phase volume than was that of WPI-stabilized nanoemulsions, and the most stable nanoemulsions were achieved when the fraction of oil reached $25 \%$. This was owing to the narrower and

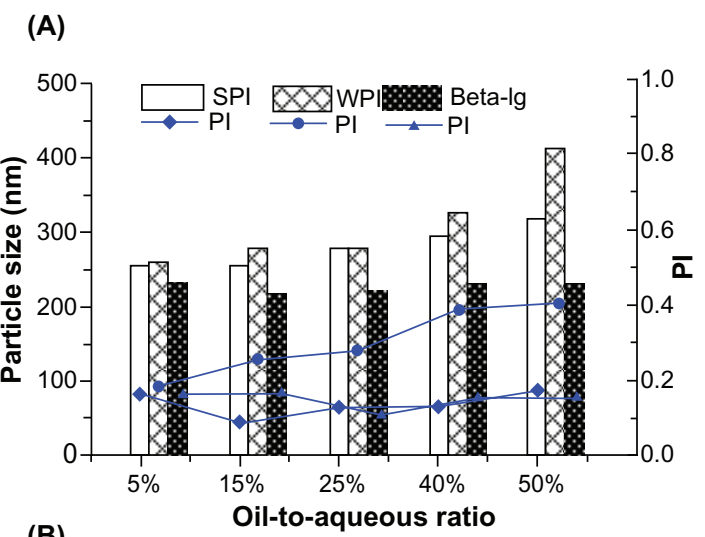

(B)

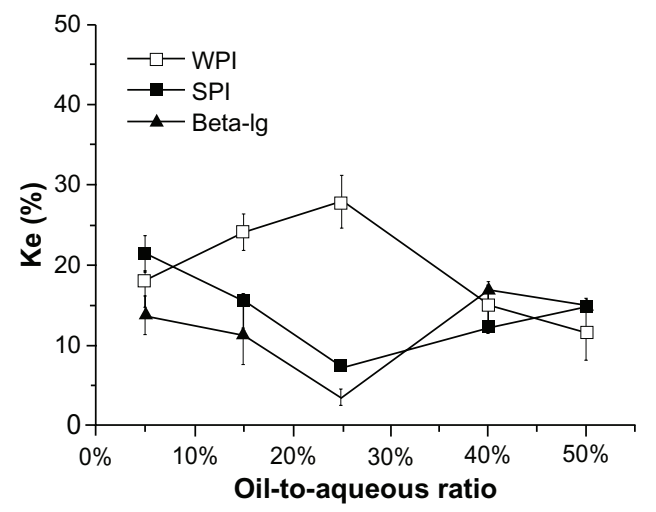

Figure 4 Effect of oil-to-water ratio on centrifugal stability (Ke), mean particle size, and polydispersity index $(\mathrm{PI})$ of protein-stabilized nanoemulsions. The concentration of protein in aqueous phase was $1.5 \%$ (wt\%). The nanoemulsions were prepared using the optimized processing conditions, ie, 800 bars and 10 cycles. A) Effect of oil-to-water ratio on mean particle size (column graph) and PI (line graph). B) Effect of oil-to-water ratio on Ke.

Abbreviations: $\beta$-lg, $\beta$-lactoglobulin; SPI, soy protein isolate; WPI, whey protein isolate.

log-normal size distribution without large particles at $25 \%$ fraction (data not shown). Compared with the nanoemulsions stabilized by WPI and SPI, the stability of $\beta$-lg-stabilized nanoemulsions was better, which was attributable to the exposure of more surface charge and hydrophobic domains.

\section{Effect of $\mathrm{pH}$}

The electrical barrier or surface charge plays a very important role in stabilizing nanoemulsions. Because proteins are zwitterionic, the nanoemulsions stabilized by food proteins in this study are differentially charged subject to $\mathrm{pH}$ variation. The effect of $\mathrm{pH}$ on nanoemulsion stabilization by proteins is shown in Figure 5.

A negligible influence of $\mathrm{pH}$ on the particle size of nanoemulsions was observed (Figure 5A). When the $\mathrm{pH}$ was increased from 7 to 10 , the PI was less than 0.3 , indicating a good monodispersivity of the nanoemulsions.

As shown in Figures 5B and 5C, there was a large influence of $\mathrm{pH}$ on the zeta potential and stability of nanoemulsions. 

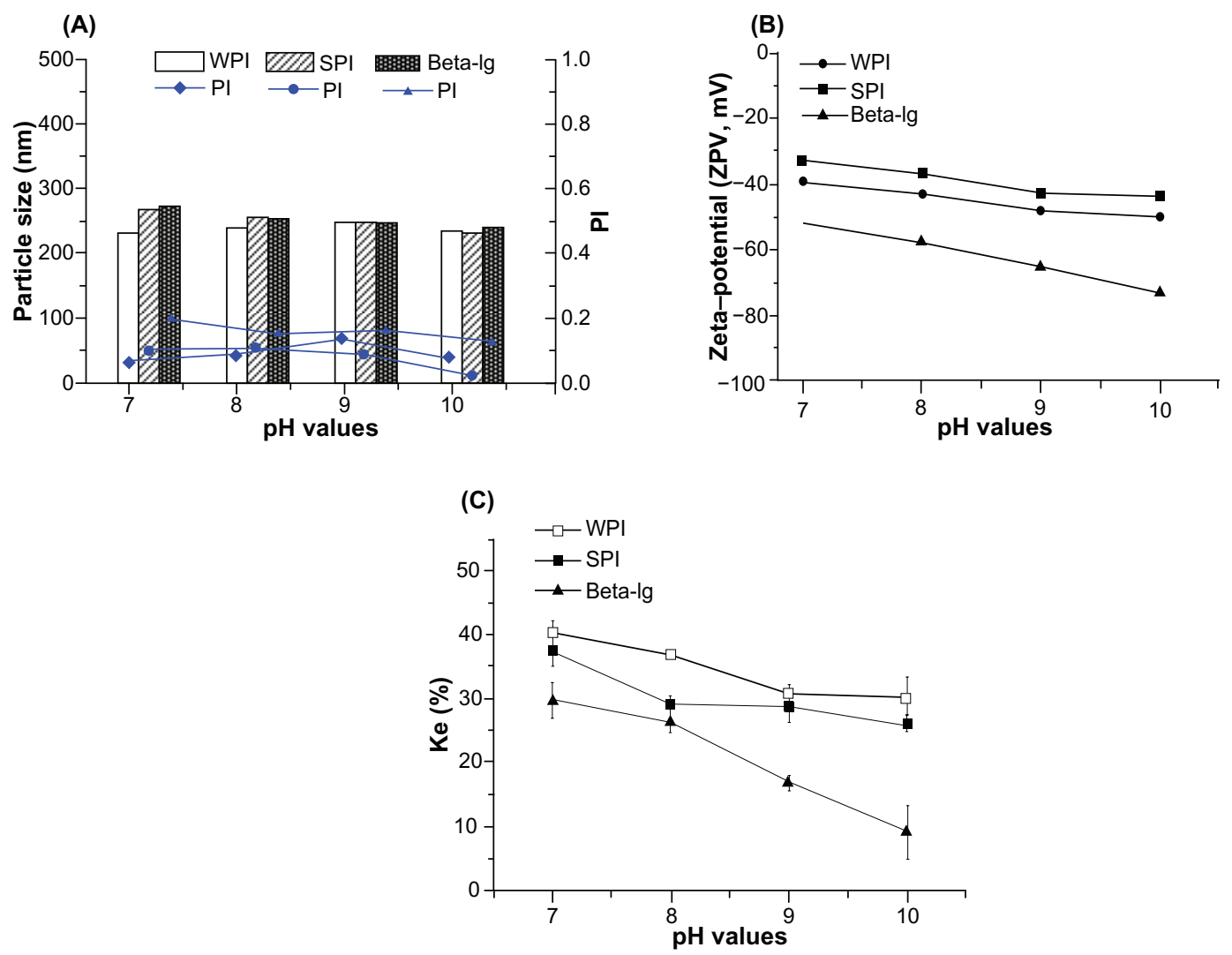

Figure 5 Effect of $\mathrm{pH}$ on particle size, polydispersity index (PI), centrifugal stability (Ke), and zeta potential of food protein-stabilized nanoemulsions. The nanoemulsions were prepared using the optimized processing conditions, ie, 800 bars and 10 cycles. A) Effect of $\mathrm{pH}$ on mean particle size (column graph) and $\mathrm{PI}$ (line graph). B) Effect of pH on zeta potential. C) Effect of $\mathrm{pH}$ on $\mathrm{Ke}$.

Abbreviations: $\beta$-lg, $\beta$-lactoglobulin; SPI, soy protein isolate; WPI, whey protein isolate.

The zeta potential ranged from $-33 \mathrm{mV}$ to $-43 \mathrm{mV},-39 \mathrm{mV}$ to $-50 \mathrm{mV}$, and $-52 \mathrm{mV}$ to $-73 \mathrm{mV}$ for SPI-, WPI-, and $\beta$-lg-stabilized nanoemulsions, respectively. The preceding results suggest an improvement in the stability of the nanoemulsions because at larger zeta potentials colloidal nanodispersions are more likely to be stable as the charged droplets within them more strongly repel one another, thus overcoming the natural tendency to aggregate. ${ }^{45,46}$ Increasing the $\mathrm{pH}$ led to a reduction in $\mathrm{Ke}$ (Figure $5 \mathrm{C}$ ), demonstrating that nanoemulsion stability was improved. The resultant stability was consistent with the zeta potential results showing that increased $\mathrm{pH}$ contributed to nanoemulsion stability. Furthermore, $\beta$-lg-stabilized nanoemulsions displayed greater stability with higher absolute values of zeta potential. This could be explained by the exposure of more hydrophobic domains on the surface of $\beta$-lg than WPI and SPI.

\section{Comparison of proteins and surfactants as emulsifiers}

Figure 6A shows the effect of different emulsifiers on the particle size and PI. The particle size of $\beta$-lg-stabilized blank nanoemulsions was similar to that of nanoemulsions stabilized by traditional surfactant emulsifiers but with lower PI. The preceding results suggest that $\beta$-lg has the same emulsification capacity as traditional surfactant emulsifiers, producing a narrower size distribution. The particle sizes of WPI- and SPI-stabilized blank nanoemulsions were slightly larger $(P<0.05)$ than those of traditional surfactant-stabilized nanoemulsions; however, the PIs were smaller, suggesting a narrower size distribution.

In nanoemulsions containing $\mathrm{FB}$, the particle size and PI of WPI- and SPI-stabilized nanoemulsions were decreased. This was possibly due to the reduction in surface tension caused by FB, which may partition at the oil/water interface and thus act as a coemulsifier. The synergistic effect of drugs and emulsifiers on the particle size of emulsions was also reported by other researchers. ${ }^{47,48}$

Figure 6B shows the effect of different emulsifiers on the zeta potential and stability of nanoemulsions. All the Ke values of protein-stabilized nanoemulsions with or without FB were lower than those of nanoemulsions stabilized with surfactants, though the difference between the nanoemulsions 
(A)

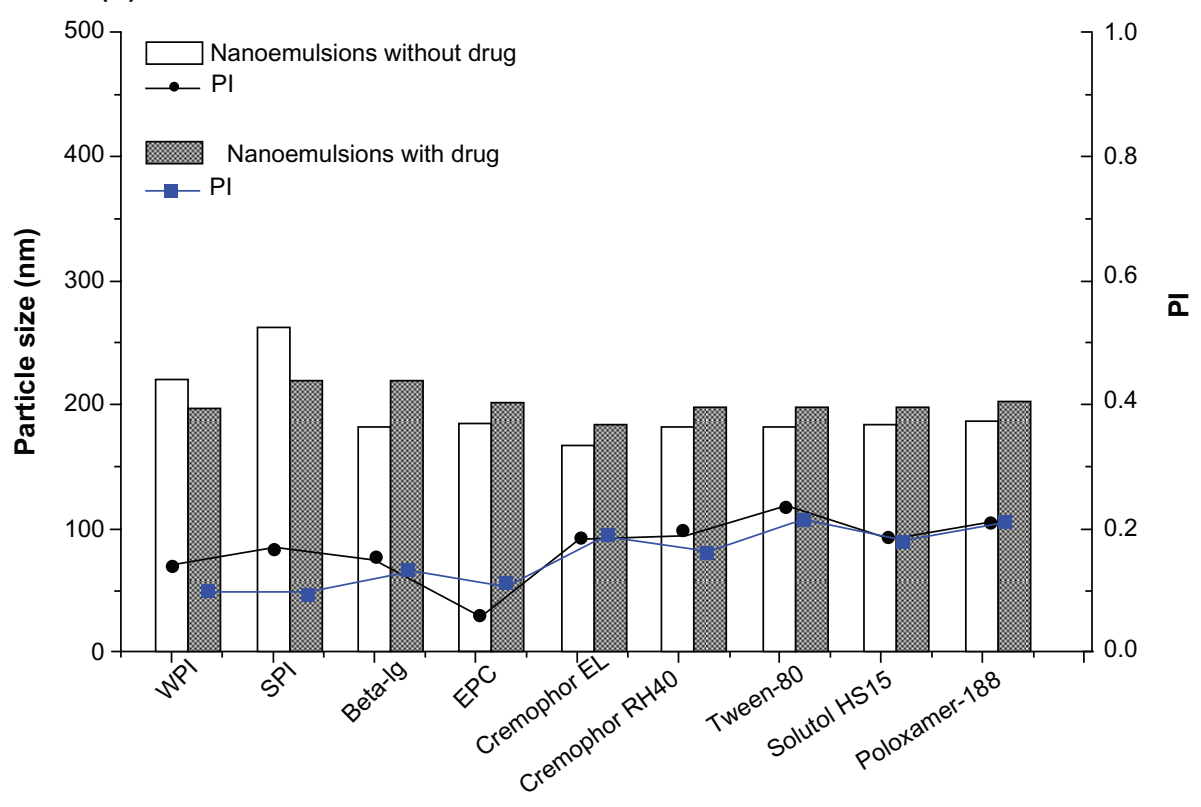

(B)

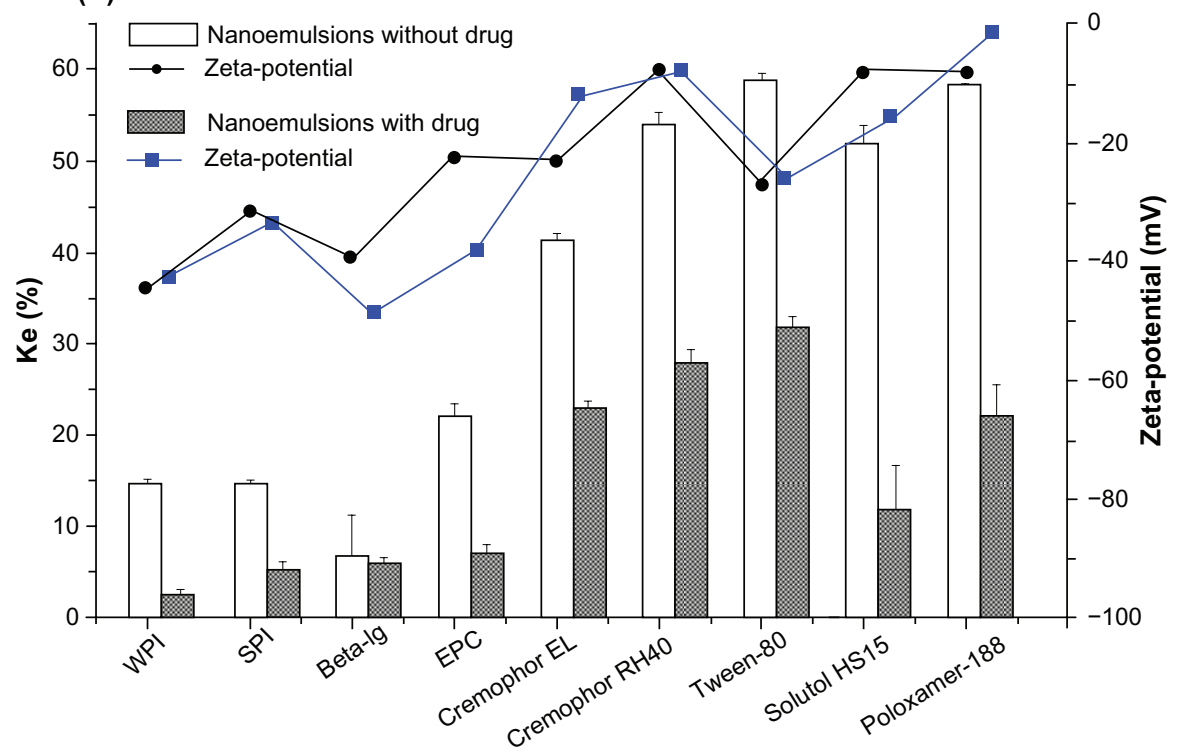

Figure 6 A) Effect of different emulsifiers on mean particle size and polydispersity index (PI) of food protein-stabilized nanoemulsions with/without drug. The amount of emulsifier in the nanoemulsion formulations was $24 \%$ (wt\%) based on the oil phase. The nanoemulsions were prepared using the optimized processing conditions, ie, 800 bars and 10 cycles (particle size [column graph] and PI [line graph]). B) Effect of different emulsifiers on Ke and zeta potential of food protein-stabilized nanoemulsions with/without drug. The amount of emulsifier in the nanoemulsion formulations was $24 \%$ (wt $\%$ ) based on the oil phase. The nanoemulsions were prepared using the optimized processing conditions, ie, 800 bars and 10 cycles (Ke [column graph) and zeta potential [line graph]).

Abbreviations: $\beta$-lg, $\beta$-lactoglobulin; SPI, soy protein isolate; WPI, whey protein isolate.

stabilized by EPC and $\beta$-lg-stabilized nanoemulsions was not significant when the drug was incorporated. It was indicated that a better stabilization was achieved when the three proteins were used as emulsifiers. To understand the underlying mechanisms, we measured the zeta potentials of these systems. It is known that greater zeta potentials correspond to more stable nanoemulsions, with absolute values above
$30 \mathrm{mV}$ being regarded as an indication of stability and enhanced uniformity through the generation of repulsive forces among particles that prevent aggregation. ${ }^{45,49}$ The zeta potentials of all protein-stabilized nanoemulsions were below $-30 \mathrm{mV}$, having absolute values significantly greater than nanoemulsions stabilized by traditional emulsifiers $(P<0.05)$. Furthermore, the steric force, which was weak 
in small molecular surfactant-stabilized nanoemulsions, was also beneficial to the improvement in stability. Notably, that additional improvement in stability observed for WPIand SPI-stabilized nanoemulsions containing FB was similar to that of nanoemulsions stabilized with traditional emulsifiers. The preceding observation was likely due to the synergistic effect of drug and emulsifier. ${ }^{47,48}$

\section{In vitro cytotoxicity of nanoemulsions}

Figure 7 shows the cytotoxicity of food protein-stabilized nanoemulsions to monolayers of Caco-2 cells. At low concentrations of emulsifier $(0.5 \mathrm{mg} / \mathrm{mL})$, no cytotoxicity of the protein-, EPC-, and Poloxamar-188-stabilized nanoemulsions was observed after a 4-hour incubation compared with the negative control. However, significant cytotoxicity was observed for the nanoemulsions stabilized by traditional emulsifiers $(P<0.05)$. When the emulsifier concentration was increased to $2 \mathrm{mg} / \mathrm{mL}$, the viability of cells treated with EPC and food protein-stabilized nanoemulsion remained greater than $95 \%$ relative to the negative control, whereas the viability of cells treated with surfactant-stabilized nanoemulsions decreased dramatically compared with controls $(P<0.01)$. At $3 \mathrm{mg} / \mathrm{mL}$ of emulsifier, the viability of cells exposed to food protein-stabilized nanoemulsions was greater than $85 \%$. For other traditional emulsifiers including EPC, a $3 \mathrm{mg} / \mathrm{mL}$ concentration caused a significant decrease in cell viability $(P<0.01)$. Importantly, the food proteins had a better biocompatibility compared with EPC, though it is well known that lecithin is not toxic. The results indicated

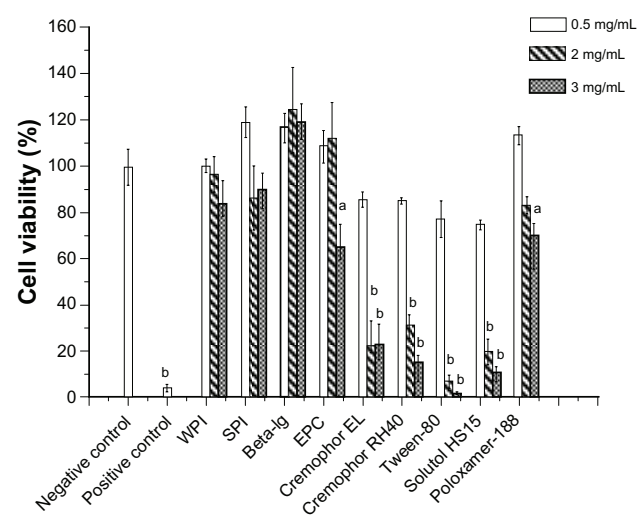

Figure 7 Effect of different emulsifiers on Caco-2 cell viability as determined by 3-(4,5-dimethylthiazol-2-yl)-2,5-diphenyltetrazoliumbromide assay following 4-hour incubation with blank nanoemulsion stabilized by food proteins or other emulsifiers. Error bars indicate standard deviation of five independent measurements. Notes: aSignificance with respect to negative control $(P<0.05)$. ${ }^{\text {bSignificance with }}$ respect to negative control $(P<0.01)$.

Abbreviations: $\beta$-lg, $\beta$-lactoglobulin; SPI, soy protein isolate; WPI, whey protein isolate. good biocompatibility of $\beta$-lg-, SPI-, and WPI-stabilized nanoemulsions. This was likely due to the protective effect of the proteins on the cells, which is in agreement with the results of Han et $\mathrm{al}^{26}$ showing that protein (bovine serum albumin) nanoparticles have no cytotoxic effect on cells. In addition, the increased hydrophilicity of the surfaces also reduces cytotoxicity. Notably, no concentration-dependent cytotoxicity of $\beta$-lg-stabilized nanoemulsions was observed. The preceding result is in agreement with that of a previous report indicating that protein-based biofilms can increase cell viability. ${ }^{50}$

\section{In vitro drug release}

The in vitro release of FB from the nanoemulsions is shown in Figure 8. Less than $10 \%$ of the drug was released in SGF

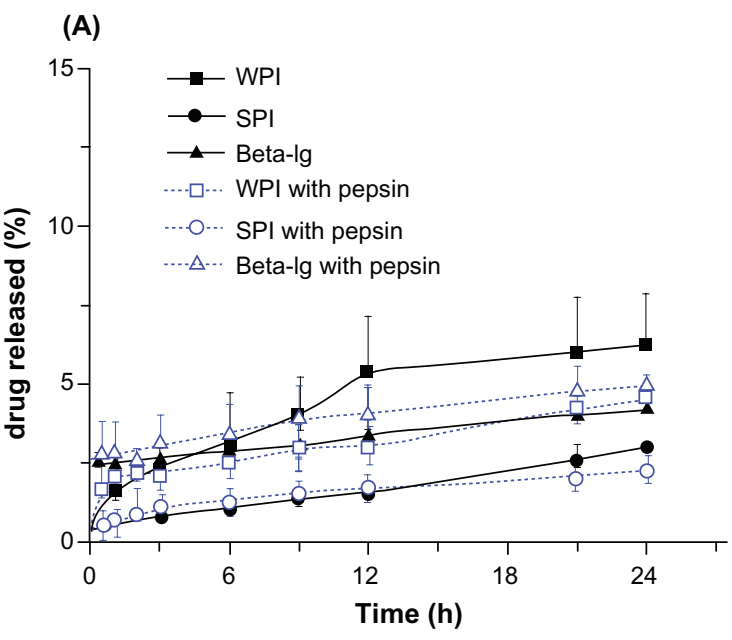

(B)

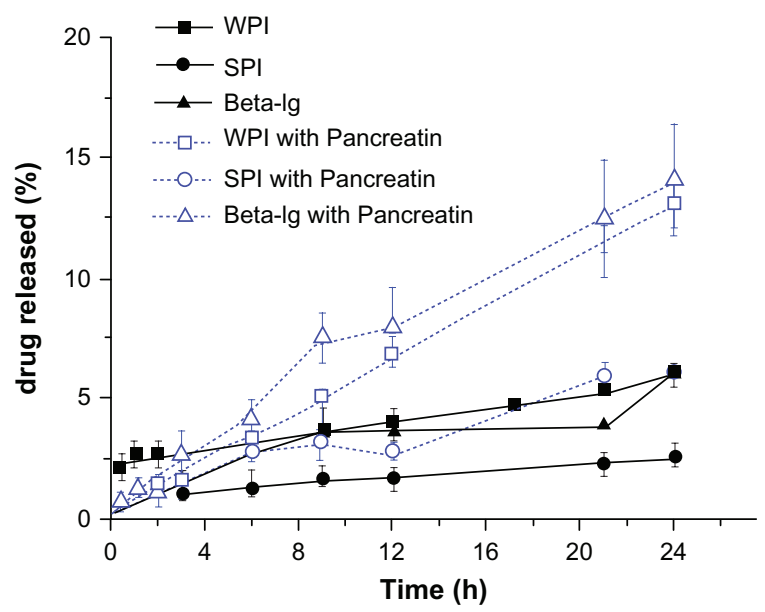

Figure 8 In vitro release profiles of fenofibrate from protein-stabilized nanoemulsions at $37^{\circ} \mathrm{C}$ in simulated gastric fluid $(\mathbf{A})$ or simulated intestinal fluid (B) containing $2 \%$ $(w / v)$ Cremophor EL.

Abbreviations: $\beta$-lg, $\beta$-lactoglobulin; SPI, soy protein isolate; WPI, whey protein isolate. 


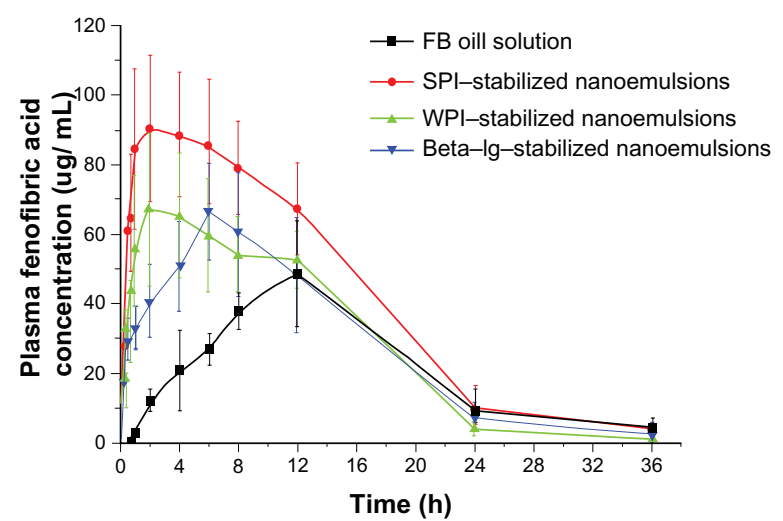

Figure 9 Plasma fenofibric acid concentration as a function of time after a single oral dose of $30 \mathrm{mg} / \mathrm{kg}$ equivalents of SPI-, WPI-, and $\beta$-lg-stabilized nanoemulsions or an oil solution of fenofibrate $(n=5)$.

Abbreviations: $\beta$-lg, $\beta$-lactoglobulin; SPI, soy protein isolate; WPI, whey protein isolate.

or SIF without digestive enzymes due to the poor water solubility of the drug. To test the effect of digestive enzymes on drug release, we added the digestive enzymes pepsin and pancreatin to the SGF and SIF, respectively. The percentage drug release in SGF was not increased in the presence of pepsin, indicating that the proteins resist pepsin degradation in the gastrointestinal tract (Figure 8A). Pepsin is known to preferentially cleave peptide bonds between hydrophobic aromatic amino acids; however, the hydrophobic amino acids that are adsorbed to the surface of the oil droplets are trapped inside the protein during the preparation of nanoemulsions. ${ }^{51}$ The hydrophobic amino acids are thus hidden, protecting them from pepsin degradation. A significant increase in drug release was observed on addition of pancreatin to SIF (Figure 8B), owing to pancreatic degradation of the proteins. ${ }^{27}$ A similar report by Chen and Subirade ${ }^{52}$ also demonstrated that pancreatic digestion promoted drug release from microparticles based on the proteins they contained. It seems that, to some extent, desirable enteric properties of proteinstabilized nanoemulsions can be achieved, which is useful for delivering a hydrophobic and acid-labile drug to the intestine.

\section{Pharmacokinetic studies}

Mean plasma fenofibric acid concentration versus time profiles following a single oral dose of the four formulations are shown in Figure 9. Mean values of the pharmacokinetic parameters are summarized in Table 1.

The $T_{\max } / C_{\max }$ of fenofibric acid from $\beta$-lg-, WPI-, and SPI-stabilized nanoemulsions was $5.60 \pm 2.19 \mathrm{~h} / 68.61 \pm$ $16.94 \mu \mathrm{g} / \mathrm{mL}, 4.00 \pm 2.45 \mathrm{~h} / 78.06 \pm 7.07 \mu \mathrm{g} / \mathrm{mL}$, and $3.40 \pm$ $2.79 \mathrm{~h} / 109.11 \pm 14.36 \mu \mathrm{g} / \mathrm{mL}$, respectively. In case of the oil solution, $C_{\max }$ was $51.35 \pm 15.31 \mu \mathrm{g} / \mathrm{mL}$ and $T_{\max }$ was $11.00 \pm 2.00 \mathrm{~h}$, both of which differed significantly from the values obtained with protein-stabilized nanoemulsion formulations $(P<0.05)$. The previous observation indicates that the drug was absorbed more rapidly when the nanoemulsions were administered orally. The $A U C$ values of $\beta$-lg-, WPI-, and SPI-stabilized nanoemulsions were $1048.31 \pm$ $266.76,1047.32 \pm 148.09$, and $1496.38 \pm 188.13 \mu \mathrm{g} \cdot \mathrm{h} / \mathrm{mL}$, which were significantly greater than those of the oil solution $(755.85 \pm 176.37 \mu \mathrm{g} \cdot \mathrm{h} / \mathrm{mL})$. The absorption of FB from nanoemulsions resulted in a significant increase in bioavailability compared with the oil solution. The lower bioavailability of the lipid solution (medium-chain triglyceride) was due to the fact that fast digestion of the medium-chain formulation results in significant drug precipitation in the gastrointestinal tract. ${ }^{34,53}$ Additionally, rats lack a gallbladder, and bile salts are secreted into the gastrointestinal tract continuously without a pulsatile response to food or lipids. ${ }^{54}$ Thus, drug absorption by the lipid solution in fasted rats is limited. In contrast, the bioavailability of protein-stabilized nanoemulsions was increased significantly compared with the control. It has been reported that nanoemulsions present drug in a solubilized form, and the small droplet size provides a large interfacial surface area for drug absorption. ${ }^{55,56}$ Furthermore, the droplet size of emulsified lipids can be decreased by biliary lipid secretion into the gastrointestinal tract. ${ }^{54}$ It should be noted that the bioavailability of SPIstabilized nanoemulsions was dramatically greater than that of nanoemulsions stabilized by $\beta$-lg and WPI. It is likely that

Table I Pharmacokinetic parameters after oral administration of protein-stabilized fenofibrate nanoemulsions and fenofibrate oil solutions

\begin{tabular}{lccc}
\hline Formulation & $T_{\max }(\mathbf{h})$ & $\boldsymbol{C}_{\max }(\mu \mathrm{g} / \mathrm{mL})$ & AUC \\
\hline Fenofibrate oil solution (control) & $1 \mu \mathrm{g} \cdot \mathbf{h} / \mathbf{m L})$ \\
Soybean protein isolate-stabilized nanoemulsions & $11.00 \pm 2.00$ & $51.35 \pm 15.31$ & $755.85 \pm 176.37$ \\
Whey protein isolate-stabilized nanoemulsions & $3.40 \pm 2.79^{\mathrm{a}}$ & $109.11 \pm 14.36^{\mathrm{b}}$ & $1496.38 \pm 188.13^{\mathrm{a}}$ \\
$\beta$-lactoglobulin-stabilized nanoemulsions & $4.00 \pm 2.45^{\mathrm{a}}$ & $78.06 \pm 7.07^{\mathrm{b}}$ & $1047.32 \pm 148.09^{\mathrm{b}}$ \\
\hline
\end{tabular}

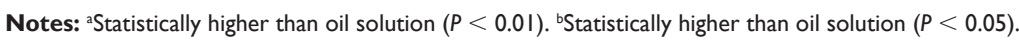

Abbreviations: $A \cup C_{0-t}$ area under the plasma concentration-time curve up to the last time; $C_{\max }$, maximum plasma concentration; $T_{\max }$, time of maximum concentration. 
SPI is more sensitive to digestion by pancreatin, leading to a further reduction in the droplet size of emulsified lipids. The results clearly demonstrate that the droplets can be stabilized by proteins, and the stabilized lipids enable a lipophilic drug to be absorbed more rapidly and better compared with oil solution.

\section{Conclusion}

Biocompatible nanoemulsions stabilized by food proteins can be produced successfully and deliver a poorly watersoluble drug in vivo. The nanoemulsions enable the lipophilic drug to be absorbed more rapidly and better when compared with the oil solution. As emulsifiers, the proteins WPI, SPI, and $\beta$-lg have better emulsifying capacity and biocompatibility than do traditional emulsifiers. A much better stability was observed in protein-stabilized nanoemulsions relative to nanoemulsions stabilized with surfactants. The preceding observation was likely due to the greater surface potential of proteins. Furthermore, $\beta$-lg-stabilized nanoemulsions exhibited greater resistance to gravitational separation and better biocompatibility compared with nanoemulsions stabilized by the other two proteins. The particle size, stability, and zeta potential were affected dramatically by protein concentration, $\mathrm{pH}$, homogenization pressure, and number of cycles. Therefore, we conclude that by using the proteins as a surfactant, the development of biocompatible and biodegradable nanoemulsion systems can be achieved, and the proteins are viable replacements for traditional surfactants.

\section{Acknowledgments}

This study was supported by the National Key Basic Research Program of China (2009CB930300, 2007CB935800) and partly by the Shanghai Commission of Education (10SG05) and the Shanghai Commission of Science and Technology (10430709200).

\section{Disclosure}

The authors report no conflicts of interest in this work.

\section{References}

1. Chen H, Khemtong C, Yang X, Chang X, Gao J. Nanonization strategies for poorly water-soluble drugs. Drug Discov Today. 2010; doi:10.1016/j. drudis.2010.02.009.

2. Amani A, York P, Chrystyn H, Clark BJ. Factors affecting the stability of nanoemulsions: use of artificial neural networks. Pharm Res. 2010;27(1):37-45.

3. Mathur AM, Drescher B, Scranton AB, Klier J. Polymeric emulsifiers based on reversible formation of hydrophobic units. Nature. 1998; 392(6674):367-370.

4. Karasulu HY. Microemulsions as novel drug carriers: the formation, stability, applications and toxicity. Exp Opin Drug Deliv. 2008;5(1): 119-135.
5. Lawrence MJ, Rees GD. Microemulsion-based media as novel drug delivery systems. Adv Drug Deliv Rev. 2000;45(1):89-121.

6. Yan A, Von Dem Bussche A, Kane AB, Hurt RH. Tocopheryl polyethylene glycol succinate as a safe, antioxidant surfactant for processing carbon nanotubes and fullerenes. Carbon. 2007;45(13):2463-2470.

7. Jiao J. Polyoxyethylated nonionic surfactants and their applications in topical ocular drug delivery. Adv Drug Deliv Rev. 2008;60(15): 1663-1673.

8. Sivakumar S, Bansal V, Cortez C, et al. Degradable, surfactant-free, monodisperse polymer-encapsulated emulsions as anticancer drug carriers. Adv Mater. 2009;21(18):1820-1824.

9. Gutiérrez JM, González C, Maestro A, et al. Nano-emulsions: new applications and optimization of their preparation. Curr Opin Colloid Inter Sci. 2008;13:245-251.

10. Trotta M, Pattarino F, Ignoni T. Stability of drug-carrier emulsions containing phosphatidylcholine mixtures. Eur J Pharm Biopharm. 2002; 53(2):203-208.

11. Sznitowska M, Janicki S, Dabrowska E, Zurowska-Pryczkowska K. Submicron emulsions as drug carriers: studies on destabilization potential of various drugs. Eur J Pharm Biopharm. 2001;12(3):175-179.

12. Chen L, Remondetto GE, Subirade M. Food protein-based materials as nutraceutical delivery systems. Trends Food Sci Tech. 2006;17(5): 272-283.

13. MaHam A, Tang ZW, Wu H, et al. Protein-based nanomedicine platforms for drug delivery. Small. 2009;5(15):1706-1721.

14. Chen LY, Subirade M. Elaboration and characterization of soy/zein protein microspheres for controlled nutraceutical delivery. Biomacromolecules. 2009;10(12):3327-3334.

15. Adachi M, Takenaka Y, Gidamis AB, et al. Crystal structure of soybean proglycinin alaB1b homotrimer. J Mol Biol. 2001;305(2):291-305.

16. Riblett AL, Herald TJ, Schmidt KA, Tilley KA. Characterization of beta-conglycinin and glycinin soy protein fractions from four selected soybean genotypes. J Agric Food Chem. 2001;49(10):4983-4989.

17. Perez OE, Wargon V, M.R. Pilosof A. Gelation and structural characteristics of incompatible whey proteins/hydroxypropylmethylcellulose mixtures. Food Hydrocolloids. 2006;20(7):966-974.

18. Davis JP, Foegeding EA. Foaming and interfacial properties of polymerized whey protein isolate. J Food Sci. 2004;69(5):C404-C410.

19. Permyakov EA, Berliner LJ. [alpha]-Lactalbumin: structure and function. FEBS Let. 2000;473(3):269-274.

20. Sawyer L. Beta-lactoglobulin. Advanced Dairy Chemistry. Vol 1. Fox PF, McSweeney LH, editors. New York: Kluwer Academic; 2003: 319-386.

21. Brownlow S, Cabral JHM, Cooper R, et al. Bovine [beta]-lactoglobulin at 1.8 resolution: still an enigmatic lipocalin. Structure. 1997;5(4): 481-495.

22. Semenova MG, Antipova AS, Belyakova LE. Food protein interactions in sugar solutions. Cur Opin Coll Int Sci. 2002;7(5-6):438-444.

23. Lee SJ, Rosenberg M. Microencapsulation of theophylline in whey proteins: effects of core-to-wall ratio. Int J Pharm. 2000;205(1-2): $147-158$.

24. Lee SJ, Rosenberg M. Preparation and properties of glutaraldehyde cross-linked whey protein-based microcapsules containing theophylline. J Control Release. 1999;61(1-2):123-136.

25. Augustin MA, Hemar Y. Nano- and micro-structured assemblies for encapsulation of food ingredients. Chem Soc Rev. 2009;38(4): 902-912.

26. Han YS, Shchukin D, Yang J, et al. Biocompatible protein nanocontainers for controlled drugs release. Acs Nano. 2010;4(5):2838-2844.

27. Chen LY, Subirade M. Alginate-whey protein granular microspheres as oral delivery vehicles for bioactive compounds. Biomaterials. 2006;27(26):4646-4654.

28. Chen LY, Remondetto G, Rouabhia M, Subirade M. Kinetics of the breakdown of cross-linked soy protein films for drug delivery. Biomaterials. 2008;29(27):3750-3756.

29. Chen L, Subirade M. Chitosan/[beta]-lactoglobulin core-shell nanoparticles as nutraceutical carriers. Biomaterials. 2005;26(30): 6041-6053. 
30. Chan OCM, So KF, Chan BP. Fabrication of nano-fibrous collagen microspheres for protein delivery and effects of photochemical crosslinking on release kinetics. J Control Release. 2008;129(2):135-143.

31. Patel AR, Vavia PR. Preparation and in vivo evaluation of SMEDDS (Self-Microemulsifying Drug Delivery System) containing fenofibrate. AAPS J. 2007;9(3):E344-E352.

32. Chen Y, Lu Y, Chen J, et al. Enhanced bioavailability of the poorly water-soluble drug fenofibrate by using liposomes containing a bile salt. Int J Pharm. 2009;376(1-2):153-160.

33. Hanafy A, Spahn-Langguth H, Vergnault G, et al. Pharmacokinetic evaluation of oral fenofibrate nanosuspensions and SLN in comparison to conventional suspensions of micronized drug. Adv Drug Deliv Rev. 2007;59(6):419-426.

34. Porter CJH, Trevaskis NL, Charman WN. Lipids and lipid-based formulations: optimizing the oral delivery of lipophilic drugs. Nat Rev Drug Discov. 2007;6(3):231-248.

35. Chen L, Remondetto G, Rouabhia M, Subirade M. Kinetics of the breakdown of cross-linked soy protein films for drug delivery. Biomaterials. 2008;29(27):3750-3756.

36. He SN, Wang DK, Li LS, et al. Preparation and characterization of docetaxel phospholipid complex submicron emulsion. Chin J Pharm. 2010;1:9-16.

37. Yang X, Wang DK, Kong LW, et al. Preparation and characteriztion of cisplatin emulsions for injection. Chin J New Drugs. 2007;16: 1376-1379.

38. Streel B, Hubert P, Ceccato A. Determination of fenofibric acid in human plasma using automated solid-phase extraction coupled to liquid chromatography. J Chromatogr B. 2000;742(2):391-400.

39. Yilmaz E, Borchert H-H. Design of a phytosphingosine-containing, positively-charged nanoemulsion as a colloidal carrier system for dermal application of ceramides. Eur J Pharm Biopharm. 2005;60(1):91-98.

40. Chu B, Wang ZL, Yu JQ. Dynamic light-scattering study of internal motions of polymer coils in dilute-solution. Macromolecules. 1991; 24(26):6832-6838.

41. Tcholakova S, Denkov ND, Sidzhakova D, et al. Effects of electrolyte concentration and $\mathrm{pH}$ on the coalescence stability of beta-lactoglobulin emulsions: experiment and interpretation. Langmuir. 2005;21(11): 4842-4855.

42. Chu BS, Ichikawa S, Kanafusa S, Nakajima M. Preparation and characterization of beta-carotene nanodispersions prepared by solvent displacement technique. J Agric Food Chem. 2007;55(16): 6754-6760.

43. Mohan S, Narsimhan G. Coalescence of protein-stabilized emulsions in a high-pressure homogenizer. J Colloid Inter Sci. 1997;192(1): $1-15$.
44. Adams JJ, Anderson BF, Norris GE, et al. Structure of bovine [beta]lactoglobulin (variant A) at very low ionic strength. J Struct Biol. 2006; 154(3):246-254.

45. Tagne JB, Kakurnanu S, Nicolosi RJ. Nanoemulsion preparations of the anticancer drug dacarbazine significantly increase its efficacy in a xenograft mouse melanoma model. Mol Pharmaceut. 2008;5(6): 1055-1063.

46. Grosse C, Pedrosa S, Shilov VN. On the influence of size, [zeta] potential, and state of motion of dispersed particles on the conductivity of a colloidal suspension. J Colloid Inter Sci. 2002;251(2):304-310.

47. Buyukozturk F, Benneyan JC, Carrier RL. Impact of emulsion-based drug delivery systems on intestinal permeability and drug release kinetics. $J$ Control Release. 2010;142(1):22-30.

48. Akkar A, Muller RH. Formulation of intravenous carbamazepine emulsions by SolEmuls technology. Eu J Pharm Biopharm. 2003;55(3): 305-312.

49. Ye SQ, Wang CY, Liu XX, Tong Z. Multilayer nanocapsules of polysaccharide chitosan and alginate through layer-by-layer assembly directly on PS nanoparticles for release. J Biomat Sci-Polym E. 2005; 16(7):909-923.

50. Gilbert V, Rouabhia M, Wang H, et al. Characterization and evaluation of whey protein-based biofilms as substrates for in vitro cell cultures. Biomaterials. 2005;26(35):7471-7480.

51. Beaulieu L, Savoie L, Paquin P, Subirade M. Elaboration and characterization of whey protein beads by an emulsification/cold gelation process: application for the protection of retinol. Biomacromolecules. 2002;3(2):239-248.

52. Chen LY, Subirade M. Effect of preparation conditions on the nutrient release properties of alginate-whey protein granular minicrospheres. EurJ Pharm Biopharm. 2007;65(3):354-362.

53. Porter CJH, Kaukonen AM, Boyd BJ, et al. Susceptibility to lipasemediated digestion reduces the oral bioavailability of danazol after administration as a medium-chain lipid-based microemulsion formulation. Pharm Res. 2004;21(8):1405-1412.

54. O'Driscoll CM. Lipid-based formulations for intestinal lymphatic delivery. Eur J Pharm Biopharm. 2002;15(5):405-415.

55. Tan A, Simovic S, Davey AK, et al. Silica-lipid hybrid (SLH) microcapsules: a novel oral delivery system for poorly soluble drugs. J Control Release. 2009;134(1):62-70.

56. Shah NH, Carvajal MT, Patel CI, et al. Self-emulsifying drug delivery systems (SEDDS) with polyglycolyzed glycerides for improving in vitro dissolution and oral absorption of lipophilic drugs. Int J Pharm. 1994;106(1):15-23.
International Journal of Nanomedicine

\section{Publish your work in this journal}

The International Journal of Nanomedicine is an international, peerreviewed journal focusing on the application of nanotechnology in diagnostics, therapeutics, and drug delivery systems throughout the biomedical field. This journal is indexed on PubMed Central, MedLine, CAS, SciSearch $®$, Current Contents $® /$ Clinical Medicine, Journal

\section{Dovepress}

Citation Reports/Science Edition, EMBase, Scopus and the Elsevier Bibliographic databases. The manuscript management system is completely online and includes a very quick and fair peer-review system, which is all easy to use. Visit http://www.dovepress.com/ testimonials.php to read real quotes from published authors. 